\title{
Influence of hydrophobic characteristic of organo-modified precursor on wettability of silica film
}

\author{
VIOLETA PURCAR ${ }^{1,2}$, OTILIA CINTEZA ${ }^{3, *}$, MARIUS GHIUREA ${ }^{1}$, ADRIANA BALAN ${ }^{2}$, \\ SIMONA CAPRARESCU ${ }^{4}$ and DAN DONESCU ${ }^{1}$ \\ ${ }^{1}$ National Research and Development Institute for Chemistry and Petrochemistry ICECHIM, Splaiul Independentei \\ no. 202, 6th district, P.O. Box 35-174, 060021 Bucharest, Romania \\ ${ }^{2}$ Faculty of Physics, University of Bucharest, 3Nano-SAE Research Centre, P.O. Box MG-38, \\ 077125 Bucharest-Magurele, Romania \\ ${ }^{3}$ Faculty of Chemistry, University of Bucharest, Bd. Regina Elisabeta 4-12, 1st district, Bucharest, Romania \\ ${ }^{4}$ Faculty of Applied Chemistry and Materials Science, University Politehnica of Bucharest, 1-7 Polizu St., 011061, \\ Bucharest, Romania
}

MS received 20 November 2012; revised 8 March 2013

\begin{abstract}
The objective of this study is to design new hybrid silica materials as templates with hydrophobic properties, prepared at room temperature by a base catalyzed sol-gel process. As silica sources, organoalkoxysilanes functionalized with short hydrophobic chains were used: tetraethylorthosilicate (TEOS), methyltriethoxysilane (MTES), vinyltriethoxysilane (VTES), octyltriethoxysilane (OTES) and isobutyltriethoxysilane (iTES). It was shown that hydrophobicity of the functionalized silica nanoparticles increased as a function of length of the aliphatic chains (MTES < iTES < OTES) or when, instead of a hydrophobic alkyl chains (substituting group of silica precursors), a monounsaturated group was used (VTES). It was observed that the samples responded in a specific way to each type (hydrophilic or hydrophobic) of the dropped liquid. Even though the experiments were limited to short hydrocarbon chains, they showed that there is a threshold to reach high hydrophobicity of the hybrid surface.
\end{abstract}

Keywords. Hydrophobic surfaces; silica hybrids; sol-gel process; hydrophobic silica; coatings.

\section{Introduction}

Although advances in nanotechnology have developed different inks, coatings and materials with super-hydrophobic properties, still a big leap is needed to be performed to the nature of mimicking. In spite of the impressive achievements with super-hydrophobic nanomaterials, specific surface treatments did not succeed in designing super-hydrophobic features of waxy-carbonic networks developed by epicuticular structures of the leaves. A shortly revisited point of views from biologists and material scientists have shown what kind of structures and organic functions need to be approached. Until now, there is no organic carbon template to develop networks of waxy polymers, but organosilicon chemistry supplies a series of alkoxides with different organic moieties which can be designed as templates with hydrophobic properties.

The objects with surfaces enriched with self-cleaning features have gained very wide applications such as proofing to snow, water, fog and pollution guarding, antioxidation, submarine, radar, etc (Fang et al 2007). The surfaces with properties of self-cleaning is a broader concept, which exploits the droplets dynamics on the hierarchically organized

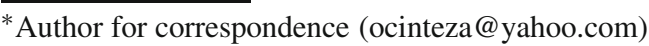

structures with features of hydrophobicity aiming to maximize repelling or dirt removal when the water falls on it. The commercial products which claim various superhydrophobicity properties (paints or surface treatments) are tributary to the development of static nanostructures: surfaces with high roughness texture, functionalized with hydrophobic moieties or recently, the direct replicating of lotus surface (Sun et al 2005). The experimental methods dealt with development of super-hydrophobic surfaces mimicking the conical spikes with subsequent functionalizing or to find other materials with hydrophobic features (topdown methods): sol-gel (Yoon and Kim 2001; Wang et al 2011; Yao et al 2011), selective solvent etching (Youngblood and McCarthy 1999; Lee et al 2006), mechanical treatment (Xie et al 2004; Yao et al 2006), carbon nanotubes alignment ( $\mathrm{Li}$ et al 2002; Lau et al 2003), silylation/silanization (Sun et al 2007), etc. Sol-gel process still remains the most appropriate when different spikes or spheres of colloidal silica with various functions, unreachable by other techniques, can be designed (Manocha et al 2000; Venkatathri 2007; Lee et al 2009; Park et al 2009; Yu et al 2009; Latthe et al 2010; Na et al 2010; Prasad et al 2011). The size of particles and pores can be controlled at the chemical solution stage (Liu et al 2009), respectively by varying the catalyst/solvent ratio (Shchipunov et al 2005; Kulkarni et al 2006; Lesellier et al 2006). In case of 
silicon alkoxides with different functional groups (methyl, vinyl, isopropyl, octyl), size and morphology of the silica nanoparticles can be tailored directly by the hydrolysis reactions in aqueous solutions, in single or multi-step processes, taking into account the strongly dependent kinetics (Beganskienè et al 2004; Tabatabaei et al 2006; Donescu et al 2008; Nistor et al 2011a, b). The versatility of sol-gel process makes it affordable to design appropriate nanostructures with functionalities close to the plant waxes which are found in their cuticle.

The aim of this contribution is to show the influence of different organic chains attached on silica nanoparticles which accomplish hydrophobic properties related to the solvents with different polarities (high hydrophilic-water, glycerol; high hydrophobic- $\alpha$-bromonaphthalene; intermediate, dimethylsulfoxide (DMSO). Five types of ethoxy silicate precursors were taken into consideration, aiming to evaluate the role of alkyl chain length-tetraethyl orthosilicate (TEOS), methyltriethoxysilane (MTES), isobutyltriethoxysilane (iTES), octyltriethoxysilane (OTES) — or the effect of using a mono-unsaturated substituting group in the silica precursor molecule-vinyltriethoxysilane(VTES). All the silica materials were prepared by sol-gel reactions of the precursors in the presence of ammonia solution, as catalyst and of ethanol as solvent.

\section{Experimental}

\subsection{Materials}

The sol-gel precursors: tetraethylorthosilicate (TEOS, Merck-Schuchardt), methyltriethoxysilane (MTES) (98\%, Fluka), isobutyltriethoxysilane (iTES) (98\%, Fluka) vinyltriethoxysilane (VTES) (98\%, Fluka), octyltriethoxysilane (OTES) (97\%, Fluka), were used as purchased. Ammonium hydroxide solution (30-33\%) (Sigma-Aldrich) and ethanol (Merck) were used as received. The liquids used for tensiometry were: dimethylsulfoxide (DMSO) (Aldrich), $\alpha$-bromonaphthalene (ABN) (Aldrich) and glycerol (G) (Aldrich).

\subsection{Synthesis of sols}

Silica sols were prepared by a base catalyzed sol-gel process. Ammonium hydroxide solution (3.55 wt $\%$ ), ethanol (82 wt $\%)$ and distilled water $(11.1 \mathrm{wt} \%)$ were stirred together for $10 \mathrm{~min}$ at room temperature. The silica precursor $(3.35 \mathrm{wt} \%)$ was added to the above mixture under vigorous stirring $(500 \mathrm{rpm})$. As silica precursor, we used a tetraalkoxysilane (TEOS) or different triethoxysilanes, having a variable organic functionality: methyl (MTES), isobutyl (iTES), octyl (OTES) and vinyl (VTES). The resulting mixture was stirred continuously for another $\sim 1 \mathrm{~h}$. For the sample based on OTES, reaction mixture was stirred for a longer time $(\sim 2 \mathrm{~h})$. The final dispersions were deposited onto clean glass slides, using a small brush and were left to dry at room temperature before being used for further investigations.

\subsection{Characterizations}

The silica particles' average diameter was measured through dynamic light scattering (DLS) technique, with a Zetasizer Nano ZS (Malvern Instruments Ltd.) device, based on noninvasive back-scattering (NIBS) technology $\left(173^{\circ}\right.$ detection optics), in the range of $0.6 \mathrm{~nm}-6 \mu \mathrm{m}$. All data were collected in the scattering intensity mode related to water as dispersant. Average diameter and polydispersity index (PdI) were measured on samples diluted with distilled water $(1 \mathrm{~mL}$ of sample $/ 25 \mathrm{~mL}$ of distilled water) and dispersed by ultrasonication $(\sim 5 \mathrm{~min})$. Morphology and shape of resulting hybrid silica particles were studied by environmental scanning electron microscopy (ESEM), using a FEI-Quanta 200 microscope without any covering of the samples. ESEM images were obtained in low vacuum mode. The sols were deposited on a conductive stub and dried at room temperature. Surface's topography was evaluated by atomic force microscopy (AFM), having a Ntegra Prima Platform (NTMDT), operated in semicontact mode, using a NSG 10 cantilever (resonance frequency: 190-325 kHz, elastic constant: $5.5-22.5 \mathrm{~N} / \mathrm{m}$ ). The measurements were performed on samples deposited on glass substrates, as resulting from the experimental part. The images were recorded at $2.5 \times$ $2.5 \mu \mathrm{m}^{2}$ planar for sample TEOS and $10 \times 10 \mu \mathrm{m}^{2}$ planar for MTES, iTES, OTES or VTES. The internal structure's modifications of the dried silica hybrids was subjected to fourier transform-infrared spectroscopy (FT-IR), on potassium bromide $(\mathrm{KBr})$-based pellets, in transmission mode (400-4000 $\mathrm{cm}^{-1}$ ) with a resolution of $4 \mathrm{~cm}^{-1}$, using a Tensor 37 Bruker instrument. The wettability of the layers of silica hybrids, deposited from the sols onto glass substrates was measured by contact angle tensiometry; the response of four different liquids being tested (distilled water, dimethylsulfoxide, $\alpha$-bromonaphthalene and glycerol). The measurements were performed at room temperature, using a data physics contact angle tensiometer, equipped with a digital camera connected to PC. The static contact angle was measured by placing (with a micro syringe) a small droplet of liquid and then analysing the drop's shape with the instrument's software. The reported contact angle values were obtained as the average of five measurements (liquid droplets deposited in various regions of the film).

\section{Results and discussion}

\section{$3.1 \quad$ FT-IR spectra}

Silica surfaces can be hydrophobic, as it occurs when the surface chemical groups are mainly siloxane $(\mathrm{Si}-\mathrm{O}-\mathrm{Si})$, or hydrophilic, when exposed to silanol $(\mathrm{Si}-\mathrm{OH})$ groups on surfaces (Kukovecs et al 2001). In general, rate of acidcatalyzed hydrolysis of alkoxysilanes depend on the silicon 
site substituents (Assink and Kay 1988). Hydrolysis occurs concurrently with condensation, producing a distribution of sites of different functionalities. Deconvolution of FT-IR spectra was necessary to observe same difference between the samples. After evaluation of FT-IR spectra of silica hybrids (figure 1), a broad peak at around $3430 \mathrm{~cm}^{-1}$ was attributed to $\mathrm{O}-\mathrm{H}$ bond of $\mathrm{H}$-bonded $\mathrm{H}_{2} \mathrm{O}$, hydroxyl terminals, $\mathrm{H}$-bonded $\mathrm{OH}$ vibrations of alcohol and $\mathrm{H}$-bonded $\mathrm{Si}-\mathrm{OH}$ in chain, respectively.

$\mathrm{C}-\mathrm{H}$ stretching bands of alkyl chains appeared at around 2979 and $2900 \mathrm{~cm}^{-1}$ and these absorption bands can be used to identify the presence of unreacted precursors in silica particles. It was observed that the peak intensity increased with increasing length of the organic bridges in organic-inorganic precursors (Nakanishi et al 2007). Si-O$\mathrm{Si}$ groups were observed for all the samples which gave two absorption peaks in the spectral region between 1047 and $1086 \mathrm{~cm}^{-1}$ in the strained geometry (asymmetric stretching vibration), as the consequence of the inorganic network formation (Voronkov and Lavrent'yev 1982; Pescarmona and Maschmeyer 2001). It was observed that the intensity of $\mathrm{Si}-\mathrm{O}-\mathrm{Si}$ bands varies with the type of precursor used in synthesis, suggesting that the condensation reaction tends to form cyclic components and that different particle sizes can be expected. The growth mechanism of the siloxane oligomers is probably the same as proposed by Brown for the condensation of cyclohexyl- or phenylsilanetriol via cyclic tetramers and cubic octamers (Brown and Vogt 1965). Condensation of the functionalized silanes stops at the stage of rather small oligomers unless very active catalysts are used. Even then, hydrolysis and condensation are not complete (residual $\mathrm{Si}-\mathrm{OH}$ and $\mathrm{Si}-\mathrm{OR}^{\prime}$ groups $(R=$ terminal alkyl or functional organic group)) over rather long periods. This is probably due to steric effects of the rather bulky organic groups. The absorption vibration band around $1130 \mathrm{~cm}^{-1}$, which was assigned as the characteristic vibration of the cubic hydrogen-silsesquioxanes by Liu et al (2002), did not appear in case of sample with TEOS, whereas a new absorption peak in around $1077 \mathrm{~cm}^{-1}$ associated to $\mathrm{Si}-\mathrm{O}-\mathrm{Si}$ network structure emerged simultaneously for the other samples with hydrophobic groups. The cyclic component in case of samples with TEOS, MTES and VTES, respectively was observed at $\sim 1083 \mathrm{~cm}^{-1}$. Compared with other precursors, in case of samples with iTES and OTES, respectively Si-OSi bond was found at around $1077 \mathrm{~cm}^{-1}$. This shift toward lower wavenumbers can be due to the hydrophobic group which produces different interactions with silica matrix in sol-gel process and indicates an overall decrease of $\mathrm{Si}-\mathrm{O}$ force constant characteristic of isobutyltriethoxysilane and also octyltriethoxysilane incorporation (Deng et al 1995). Therefore, it is reasonable to consider that the reaction products obtained by the hydrolytic condensation are a mixture of species with different structures (Rikowski and Marsmann 1997).

\subsection{Particle size and topography}

Size variation of the hybrid silica particles (in average diameter, $D$ and main peak, $P_{1}$ ) is included in figure 2. DLS characterization revealed a dependence of particle size on the type of substituting organic groups from silica precursors.

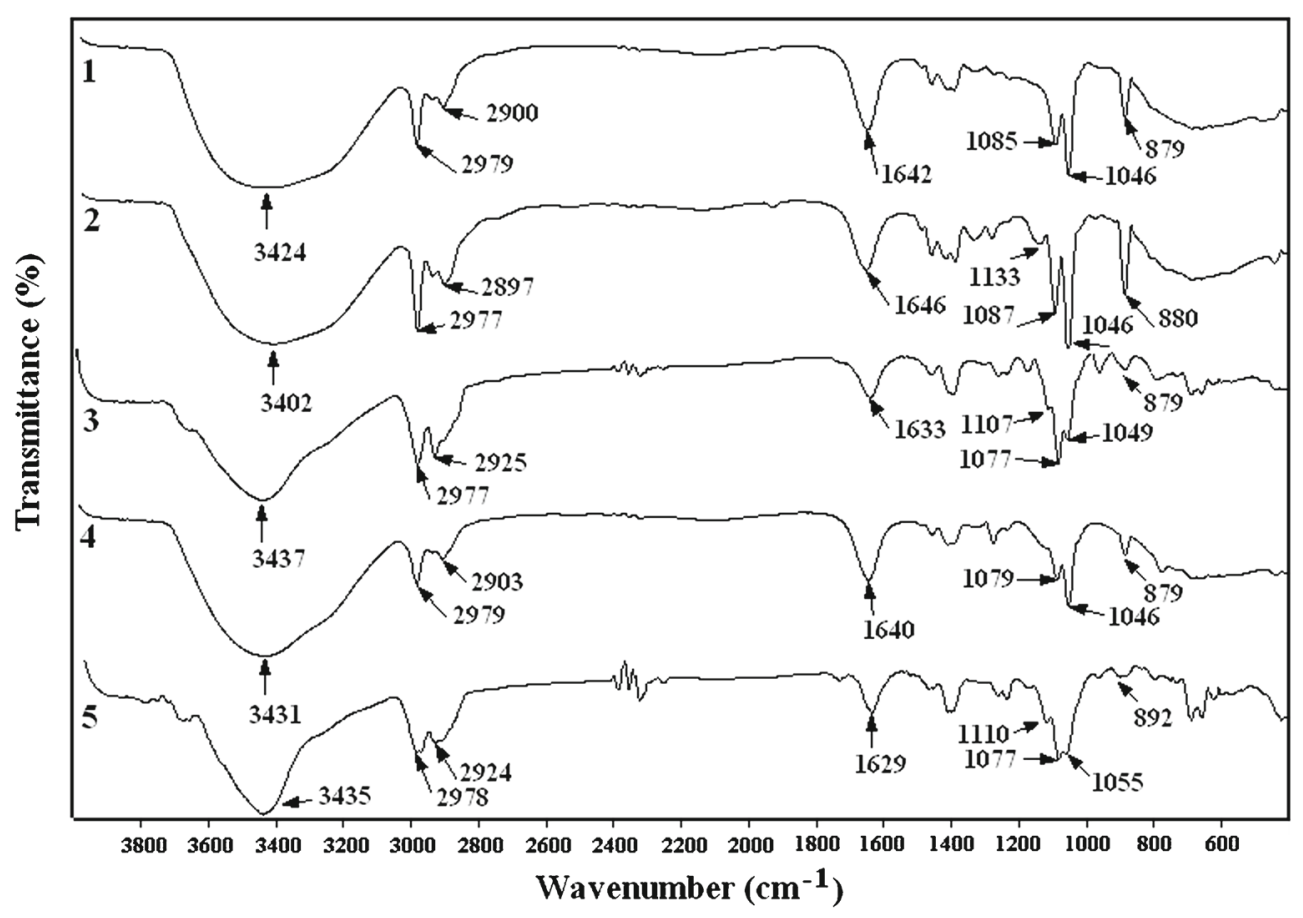

Figure 1. FT-IR spectra of hybrid materials after deconvolution, prepared with different precursors: (1) TEOS, (2) VTES, (3) OTES, (4) MTES and (5) iTES. 


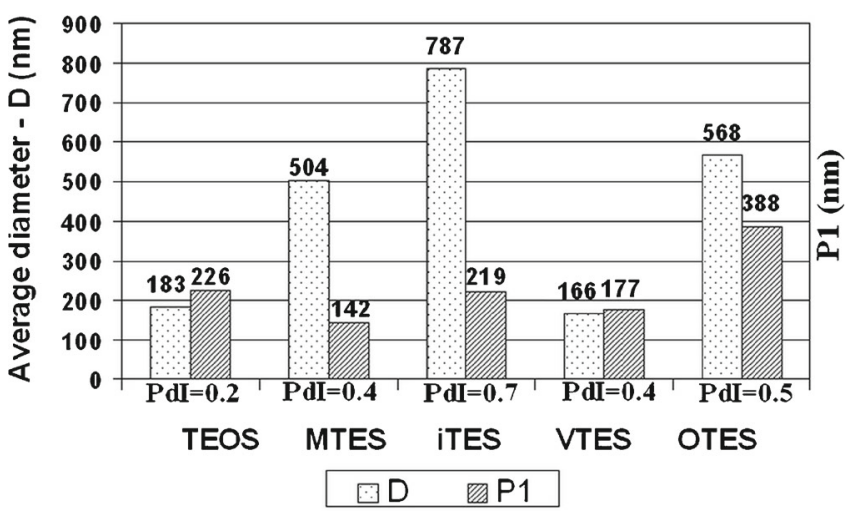

Figure 2. Dynamic light scattering (DLS) results for silica hybrid materials.

In case of sample based on TEOS, size distribution was characterized by a lower polydispersity index $(\mathrm{PdI}=0 \cdot 2)$. However, a large size distribution was observed. The lower value of $D(183 \mathrm{~nm})$, compared with $P_{1}(226 \mathrm{~nm})$, can be explained by the presence, beside the main population of silica particles (characterized by $P_{1}$ ), of smaller particles. In the previous study, it was shown that the aggregation of TEOS tends to be diffusion limited cluster-cluster aggregation (growth tends to form a network of uniform spherical clusters), under the base catalysis conditions where hydrolysis is much slower than condensation (Xiao et al 2007).

When the silica sources were MTES, iTES, OTES or VTES, respectively (one of the ethoxy groups from TEOS was replaced by a hydrophobic group), the size's polydispersity was more pronounced and this was reflected, on the one hand, by the higher value of the polydispersity index ( $\mathrm{PdI}=$ $0.4 / 0 \cdot 7$ ) and on the other hand, by the much higher values of the average diameter $(D)$, compared with the main peak $\left(P_{1}\right)$. Although the recorded main peak $\left(P_{1}\right)$ of particles indicated, in general, smaller particle sizes than those measured for the sample with TEOS, values of the average diameters $(D)$ were much higher, due to the formation of large aggregates in the hybrid systems. These results confirm that the presence of organosilanes with a diverse number of carbon chains has an influence on silica particle size. The hydrolysis of these triethoxysilanes (MTES, iTES, OTES, VTES) leads to monomeric units of the corresponding hydroxides, $\left(\mathrm{Si}(\mathrm{OH})_{3}\right)$, that act as active centres for the polycondensation of $\mathrm{Si}-\mathrm{O}-\mathrm{Si}$ network. This phenomenon leads to formation of organo-silica materials with well-tailored network structures (Nadargi and Rao 2009).

Beside DLS technique, ESEM and AFM images also made possible to see that the size distributions became polydisperse, in case of MTES, iTES, OTES or VTES. Figure 3 shows ESEM-images of the silica particles obtained from different syntheses formulations and the corresponding AFM-3D topographies taken from samples deposited on glass slides.

According to figure 3, when the sol-gel reaction is carried out with TEOS, spherical particles with diameters in the range of $0 \cdot 1-0.5 \mu \mathrm{m}$ are generated. The particle distribution is polydispersed and also confirmed by DLS measurements. Because of the higher hydrophobicity, in case of substituted silanes (VTES, MTES, OTES or iTES), the formation of large aggregates was observed. The particle-particle interaction became stronger and aggregates were formed by hydrogen bonding or condensation of the hydroxyl groups at the particle surface (Chen et al 2008).

After evaluation of the typical 3D-AFM images of the dried silica hybrids, it was found that the surface topography was strongly dependent on molecular structure of the precursor. In concurrence with ESEM data, spherical and polydisperse particles were observed on the surface of hybrid based on TEOS. For other hybrids, both AFM and ESEM images show the existence of large aggregates, consisting of nano-scaled pristine particles, which can be attributed to hydrophobic associations of new hybrid particles, starting from trialkoxy-derivatives. Comparing with TEOS sample, MTES and iTES-based hybrids are characterized by the existence of large clusters of spherical entities (different sizes, ranging from $0 \cdot 1 \mathrm{~nm}-2 \mu \mathrm{m}$ ). In case of VTES and OTES hybrids, even larger clusters are clearly visible on the dried hybrid surfaces. Thus, the samples prepared with MTES, iTES and OTES, respectively exhibit surfaces with higher roughness than that of the sample with VTES derivative. Also, it is clear from table 1 and figure 3 that the roughness depends on growth of the silica nanoparticles on a film surface. The silica films containing VTES and OTES, with large particles provide higher roughness and large amount of air entrapment which reduces the contact area of water drops with the surface.

Some differences between DLS data, obtained on dispersed hybrids and the solid-state images can be explained by the increase of hydrophobic demixing during solvent evaporation. In this state of hybrid preparation, the aggregates concentration gradually increases and at the same time, the hydrophobic associations occur.

\subsection{Contact angle measurements}

The principles of the wetting angle on the rough surface have been discussed based on the two models: Wenzel (1936), which demonstrated that the area below water droplet is fully wetted (wetted surface regime). In this case, rough surface increases the contact area between solid and liquid resulting in larger apparent wetting angle (Cassie and Baxter 1944). On the other hand, Cassie and Baxter (1944) demonstrated that the air can remain trapped below the water droplet (composite surface regime) and the composite surface leads to an increase in wetting angle because, a part of water drop sits on air (Wenzel 1936).

In this study, the wettability of silica films deposited from the obtained sols onto clean glass substrates and dried at room temperature was investigated. The behaviour of the films when put in contact with different liquid droplets is shown in figure 4 and discussed below. The surface polarity 

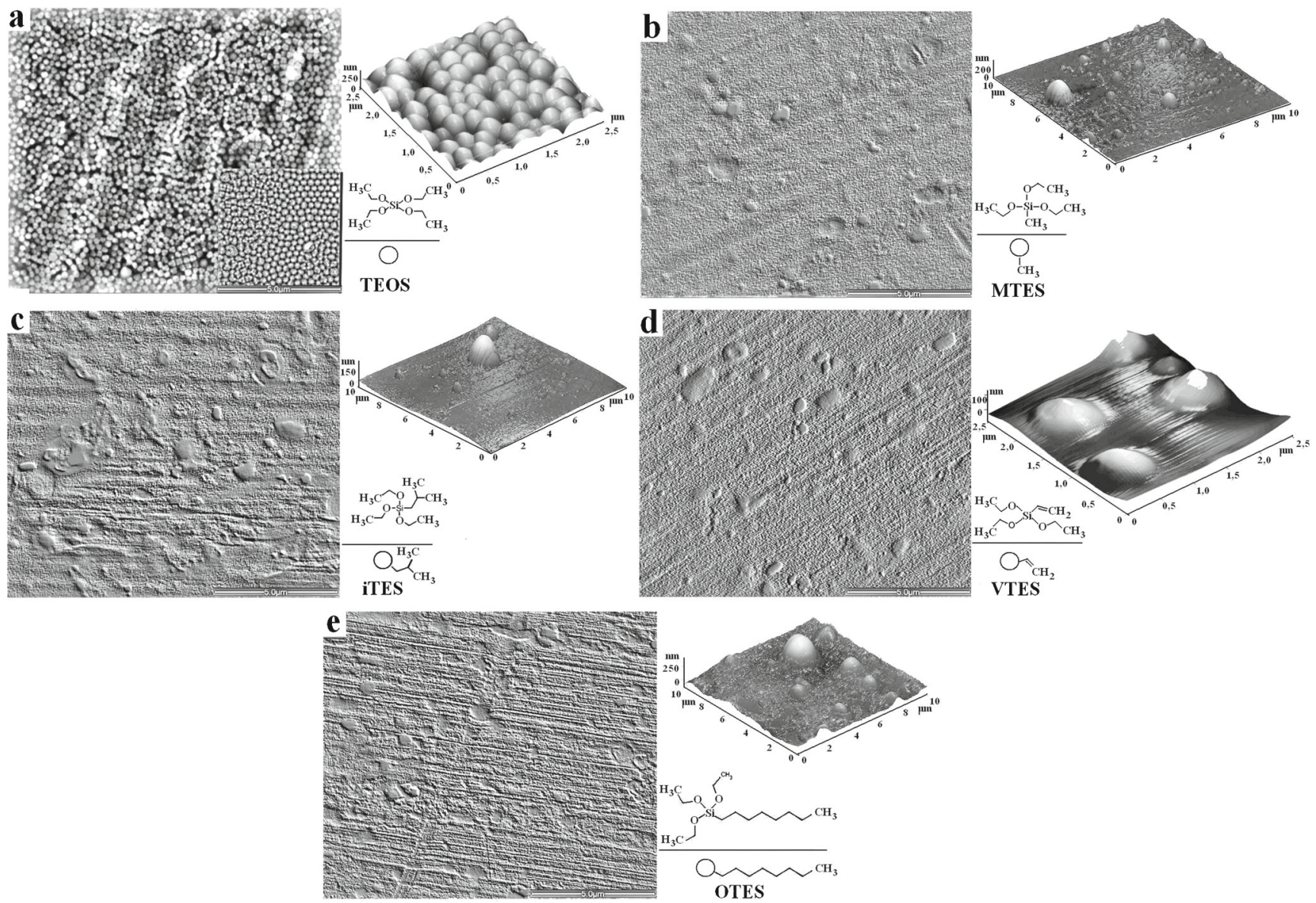

Figure 3. ESEM-images of silica particles obtained from different syntheses formulations and corresponding AFM-3D topographies taken from films deposited on glass slides.

Table 1. Average roughness of prepared silica films.

\begin{tabular}{lcc}
\hline Samples & $\begin{array}{c}\text { Average roughness } \\
(\mu \mathrm{m})\end{array}$ & $\begin{array}{c}\text { Particle size } \\
\left(P_{1}\right)(\mathrm{nm})\end{array}$ \\
\hline TEOS-hybrid & 0.362 & 226 \\
MTES-hybrid & 0.285 & Very rare particles \\
iTES-hybrid & 0.014 & Very rare particles \\
VTES-hybrid & $0 \cdot 219$ & 177 \\
OTES-hybrid & 0.396 & Very rare particles \\
\hline
\end{tabular}

of films was compared in experiments using liquids with different polarities such as high hydrophilic water and glycerol, respectively and high hydrophobic $\alpha$-bromonaphthalene. Dimethylsulfoxide was also used in experiments as a liquid of intermediary polarity.

When suspension containing only TEOS was applied on the surface, the contact angle could not be measured due to higher hydrophilic character of the surface. Because ammonia works as a basic catalyst, the hydrolysis reaction is probably initiated by the attacks of hydroxyl anions on TEOS molecules (Ibrahim et al 2010). Terminal hydroxyl groups which can interact with water leads to deterioration of the silica network (Latthe et al 2009).

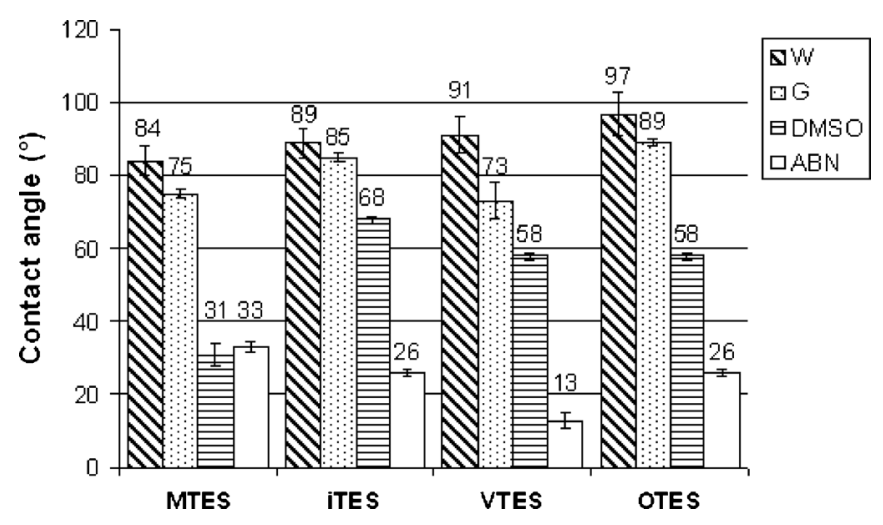

Figure 4. Contact angles of four different liquids-water (W), dimethylsulfoxide (DMSO), $\alpha$-bromonaphthalene (ABN) and glycerol $(\mathrm{G})$ on surface of dried silica hybrids, depending on different types of silica precursors (MTES, iTES, VTES and OTES); for TEOS-based hybrid, measurement could not be performed due to its high hydrophilic character.

By simple substitution of one ethoxy group of TEOS molecule with groups such as vinyl, octyl, methyl or isobutyl surfaces, a higher hydrophobic character could be obtained. This effect is observed from the value of the contact angle 
with water. The hydrophobic properties depend on the ethoxy substituting groups. These organic groups replace the hydrogen of $-\mathrm{OH}$ from the film's surface during the sol-gel process. A layer containing non-hydrolysable groups are formed on the surface and as a consequence, promote higher hydrophobicity of the hybrid surfaces. The hydrophobic character of the silica materials increases with an increase in the length of the hydrophobic chain, following the order: MTES $<$ iTES $<$ VTES $<$ OTES. The smallest value of the contact angle with water was obtained for the sample based on MTES $\left(84 \pm 4^{\circ}\right)$ which confirms a higher contribution of the non-polar groups $\left(\mathrm{CH}_{3}^{-}\right)$at the film surface. The strongest hydrophobic character of the surface is obvious for OTEShybrid $\left(97 \pm 6^{\circ}\right)$. This was an anticipated result, because its substituting group (octyl) is the most hydrophobic from the tested ones. Comparing with MTES and iTES, for VTESbased sample, the hydrophobic character is higher, probably because of the existence of some interactions between the vinyl groups (of VTES) and the hydroxyl groups from the inorganic network which is only partially condensed. It can be observed that the mono-unsaturated chain (VTES sample) leads to higher hydrophobicity than the short-saturated chains, except the octyl, which is much longer than the other hydrocarbon chains.

TEOS derivative is the only one which is able to produce a silica film with clear nanometric organization/structure. More hydrophobic silane derivatives lead to more smooth film (OTES) with rare aggregates. In this respect, the roughness of surface in the case of OTES seems not to affect considerably value of the water contact angle $\left(97 \pm 6^{\circ}\right)$. The long carbon chains on the silica surface of OTES-particles are responsible for the higher water contact angle, leading to the formation of the most hydrophobic surface (Wu et al 2007). These results are in good agreement with the size and topographic analyses and it can be concluded that the hydrophobicity depends on the larger number of non-polar ( $\mathrm{Si}-R$, where $R=$ methyl, isobutyl, vinyl, octyl) groups on the silica film surface.

Also, behaviour of the silica films was investigated by measuring the contact angle of some liquids with different polarities (glycerol, $\alpha$-bromonaphthalene, dimethylsulfoxide). The value of the contact angle with glycerol increases from $73 \pm 5^{\circ}$ (for VTES) to $89 \pm 1^{\circ}$ (for OTES), following the same variation tendency as for water. The smallest values of the contact angle were obtained when $\alpha$ bromonaphthalene $(\mathrm{ABN})$ was used. This effect is based on the reduced contribution of the polar species in the surface region. The non-polar groups from alkyl trialkoxy silane derivatives induce a specific interaction with $\alpha$ bromonaphthalene (ABN). The order of values of the contact angle is, as we expected, opposite to those of water and glycerol. For dimethylsulfoxide (DMSO), contact angle increases from $31 \pm 3^{\circ}$ (for MTES) to $68 \pm 1^{\circ}$ (for iTES). For the samples with VTES and OTES, same value of contact angle $\left(58^{\circ}\right)$ was obtained. This solvent presents strong interactions with the surface groups, in particular, with the hydroxide groups from the surfaces. These results suggest that there is a delicate balance between properties of the tested liquids and high component on the dipolar contribution of the solvents and their surface tension (Redón et al 2005).

In our experiments, morphology of the silica film obtained with various hydrophobic silane derivatives is significantly different from the film obtained from TEOS: the last one consists of a rather uniform nanostructured pattern, with the surface covered by closely packed nanoparticles. In contrast, films obtained from organo-modified precursors show larger nanoparticles formed on the silica surface, with large spaces between them. In this respect, effect of the surface nanostructure described in the Cassie-Baxter theory is lost and increase in the water contact angle is very low.

Surface polarity depends equally on (i) nature of the organic radicals of the organotrialkoxysilanes used in preparing the compositions, (ii) the extent and polarity of the inorganic patches exposed towards air, (iii) the (eventual) mutual interactions between the organic and inorganic components (Uricanu et al 2004).

The contact angle values obtained for the studied materials can be related to the surface tension or energy of the solid. The components of the surface energy (disperse and polar components) were computed using Owens-Wendt-RabelKaelble method (OWRK) (Owens and Wendt 1969; Kaelble 1970). In table 2, values of the surface energy and its components are shown for the silica films obtained from various silane derivatives.

As shown in figure 3, sample from TEOS is composed of bare silica nanoparticles with different diameters. The surface is hydrophilic with water contact angle $<10^{\circ}$. The exact contact angles of these films cannot be determined with

Table 2. Surface free energy (SE) and its dispersive (SEd) and polar component (SEp) of silica films prepared from various organo-modified silane derivatives.

\begin{tabular}{lccc}
\hline Samples & SE total (mN/m) & SEd (mN/m) & SEp (mN/m) \\
\hline MTES-hybrid & $36 \cdot 20$ & 32.50 & 3.70 \\
iTES-hybrid & 29.93 & 26.35 & 3.59 \\
VTES-hybrid & 33.53 & 31.44 & 2.10 \\
OTES-hybrid & 28.12 & 26.65 & 1.47 \\
\hline
\end{tabular}

Table 3. Polar surface area and octanol-water partition coefficient for silane reagents used to obtain silica films.

\begin{tabular}{lcc}
\hline Silane precursor & Polar surface $\operatorname{area}^{\mathrm{a}}\left(\mathrm{A}^{2}\right)$ & $\log P^{\mathrm{a}}$ \\
\hline TEOS & 36.92 & 1.68 \\
MTES & 27.69 & 1.66 \\
iTES & 27.69 & 2.84 \\
VTES & 27.69 & 2.18 \\
OTES & 27.69 & 4.42 \\
\hline
\end{tabular}

a Data from Chem Spider chemical structure database computed using ACD/Labs' ACD/PhysChem Suite. 
accuracy because, water penetrated into the silica material immediately after droplet deposition.

The total surface energy of silica films is rather high in the experimental condition of the present study, higher than

Table 4. Work of adhesion for silica film from various silane precursors.

\begin{tabular}{lc}
\hline Samples & $W_{\mathrm{a}}(\mathrm{mN} / \mathrm{m})$ \\
\hline MTES-hybrid & 79.83 \\
iTES-hybrid & 73.23 \\
VTES-hybrid & 70.97 \\
OTES-hybrid & 63.25 \\
\hline
\end{tabular}

the values reported in the literature due to the method of preparation and deposition of silica film.

The surface energy of the silica film prepared from MTES is the highest, compared with that from the more hydrophobic silane precursors, in the order MTES $<$ VTES $<$ iTES $<$ OTES. As expected, the smallest surface energy is obtained for OTES, with the long hydrocarbon chain in the molecule of the silane reactant. In case of OTES, the dispersive component is comparable with SEd of the films prepared with iTES, with a significantly low-polar component due to the presence of octyl groups in the surface of the film. Similar value for the dispersive surface energy results for VTES and MTES films, but the polar component in case of MTES is higher. The silane reagents MTES, iTES and VTES, with rather short hydrocarbon groups exhibit polar component in the range $3 \cdot 70 / 2 \cdot 10 \mathrm{mN} / \mathrm{m}$.
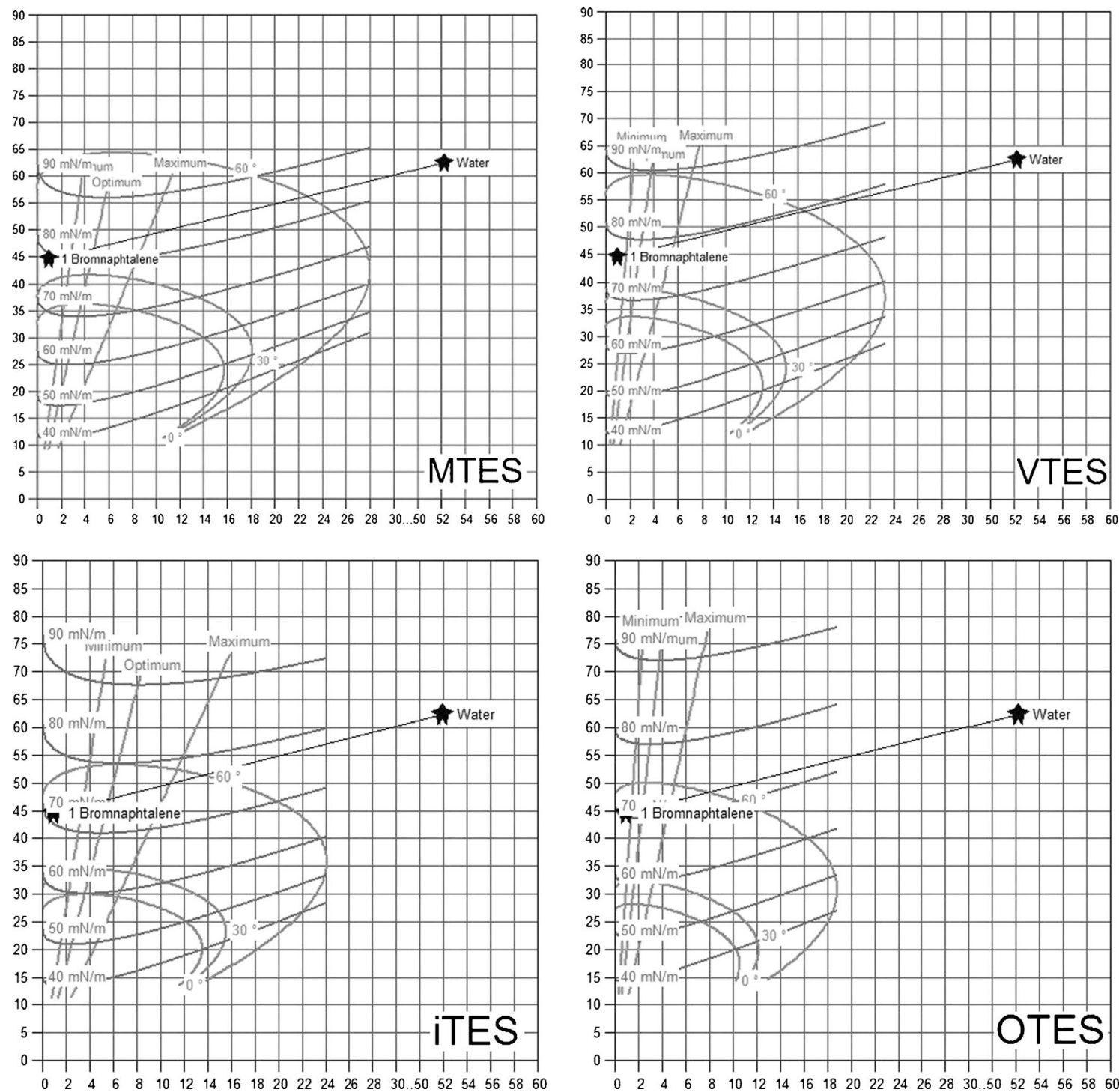

Figure 5. Diagrams of work of adhesion for silica films prepared from organo-modified silica precursor with liquid surface tension (SFT) and liquid polar contribution of SFT in $\mathrm{mN} / \mathrm{m}$ on horizontal and vertical axis. Isolines are depicted in red, optimum adhesion corridor (vertical lines) is in green and wetting envelopes in blue (between 0 and $60^{\circ}$ ). 
The difference in the polar component of the surface energy could be explained in terms of the difference of dipole moments of the molecules end group or other physico-chemical characteristics, that described the molecule hydrophobicity, such as polar surface area and octanol-water partition coefficient. The descriptors of the silane derivatives are summarized in table 3 .

As expected, OTES which have molecules with very small dipole moment and the highest $\log P$ value exhibits a small polar contribution to surface energy. The values of the octanol-water partition coefficient correlate well with variation of the polar component of the surface energy in the series MTES > VTES > iTES > OTES. In contrast, polar surface area of the silane molecules does not influence the values of SEp.

The variation of the surface free energy and its components for the silica film prepared in this work could not be related in a simple manner only to the hydrophobicity of the reactants (due to the chemical nature of the organomodified silane), since the solid substrate is not obtained as self-assembled monolayer with a selective orientation of the organic groups on the surface. The values of the surface energy for the silica thin films obtained by spreading the material prepared in a sol-gel reaction should reflect the contribution of the ratio of organic patches in $\mathrm{SiO}_{2}$ matrix exposed to the surface. Thus, variation in the extent of dispersive and polar components of the surface energy is due both to the differences in the hydrophobicity of the precursor molecule and presence of the hydroxyl groups formed during the sol-gel process together with hydrophobic regions from organic groups in the film surface.

The work of adhesion, $W_{\mathrm{a}}$, was computed from the contact angle values according to the following equation:

$$
W_{\mathrm{a}}=\gamma_{\mathrm{lv}}(1+\cos \theta)
$$

where $W_{\mathrm{a}}$ is the work of adhesion of the liquid on the solid surface, $\gamma_{\text {lv }}$ the surface tension of the liquid and $\theta$ the contact angle recorded. The work of adhesion for various silica films prepared with organo-modified silane reagents are shown in table 4.

The lowest value for the work of adhesion of water on silica films is recorded for the sample obtained from OTES derivative. According to their similar hydrophobicity of the molecule, iTES and VTES films show close values of the work of adhesion, while the highest value is found for MTES derivative.

The work of adhesion diagrams for water on the solid surfaces obtained from various silane derivatives are presented in figure 5, computed using surface free energies determined as described earlier.

The isographs of the adhesion work were calculated for a polar liquid (water) and non-polar one (1-bromonaphthalene) and show similar behaviour for all the silanes used in this study.

The polar liquid (water) point is located outside the optimum adhesion corridor, as expected from the values of the calculated adhesion work. The non-polar liquid is located closer to the optimum line for all solid substrates prepared with hydrophobic silanes, but still exhibits bad adhesion to the surface. Due to the rather high surface tension, it shows a limited tendency for spreading onto the organo-modified silane film for all the four compounds.

The wetting envelope is more extended in the case of MTES derivative than gradually decreasing for the film prepared with VTES, iTES and OTES.

\section{Conclusions}

The work described above demonstrated that hybrid silica particles were obtained by sol-gel process by replacing one of the ethoxy groups of TEOS with hydrophobic chains (VTES, MTES, OTES and iTES). The size and topography of hybrid silica particles, bearing hydrophobic groups, depends on the precursor structure. Smaller and mainly spherical particles can be observed for TEOS hydrolysis and condensation reactions. In case of other samples (containing hydrophobized silica particles), ESEM and AFM images revealed the existence of some large aggregates, generated by the agglomeration of nanoscaled particles. This statement was also confirmed by DLS technique and higher values of the polydispersity index determined. It was observed that the octyl-saturated chain (of OTES) led to a higher hydrophobicity (measured by contact angle tensiometry) than the shorter chains of MTES, iTES and VTES, respectively. However, since an organosilane such as OTES has a strong hydrophobic character and monodisperse silica particles are not obtained. Choice of suitable silica precursors can create the premises for producing suitable hydrophobic silica particles for the development of hydrophobic coating technology.

\section{Acknowledgements}

This work was supported by the strategic grant POSDRU/89/1.5/S/58852, Project "Postdoctoral programme for training scientific researchers" cofinanced by the European Social Fund within the Sectorial Operational Program Human Resources Development 2007-2013? and by the Grant funded by the Romanian National Authority for Scientific Research, CNDI-UEFISCDI, project number 3.2-1391.

\section{References}

Assink R A and Kay B D 1988 J. Non-Cryst. Solids 10735

Beganskienè A, Sirutkaitis V, Kurtinaitienè M, Juškẻnas R and Kareiva A 2004 Mater. Sci. 10287

Brown J F and Vogt L H 1965 J. Am. Chem. Soc. 874313

Cassie A B D and Baxter S 1944 Trans. Faraday Soc. 40546

Chen C C, Lin D J, Don T M, Huang F H and Cheng L P $2008 \mathrm{~J}$. Non-Cryst. Solids 3543828

Deng Q, Mauritz K A and Moore R B 1995 A. C. S. Symposium Series $\mathbf{5 8 5} 66$ 
Donescu D, Somoghi R, Petcu C, Corobea M C, Ianchis R and Nistor C L 2008 U.P.B. Sci. Bull. 7039

Fang Y, Sun G, Wang T Q and Cong Q 2007 Chinese Sci. Bull. 52 711

Ibrahim I A M, Zikry A A F and Sharaf M A 2010 J. Am. Sci. 6985

Kaelble D H 1970 J. Adhes. 266

Kukovecs A, Konya Z, Pálinko I, Mönter D, Reschetilowski W and Kiricsi I 2001 Chem. Mater. 13345

Kulkarni S A, Kakade B A, Mulla I S and Pillai V K 2006 J. Colloid Interface Sci. 299777

Latthe S S, Nadargi D Y and Rao A V 2009 Appl. Surf. Sci. 255 3600

Latthe S S, Imai H, Ganesan V, Kappenstein C and Rao A V 2010 J. Sol-Gel Sci. Technol. $\mathbf{5 3} 208$

Lau K K S, Bico J, Teo K B K, Chhowalla M, Amaratunga G A J, Milne W I, Mckinely G H and Gleason K K 2003 Nano Lett. 3 1701

Lee G S, Shin Y H, Kim J M, Kimand T S and Lee Y Z 2009 J. Nanosci. Nanotechnol. 97340

Lee S M, Lee H S, Kim D S and Kwon T H 2006 Surf. Coat. Technol. 201553

Lesellier E, West C and Tchapla A 2006 J. Chromatogr. A 111162

Li S H, Li H J, Wang X B, Song Y L, Liu Y Q, Jiang L and Zhu D B 2002 J. Phys. Chem. B106 9274

Liu W C, Yang C C, Chen W C, Dai B T and Tsai M S $2002 \mathrm{~J}$. Non-Cryst. Solids 311233

Liu Q, Zhang J, Liu Q J, Zhu Z Q and Chen J 2009 Mater. Chem. Phys. 114309

Manocha L M, Yasuda E, Tanabe Y, Manocha S and Vashistha D 2000 Bull. Mater. Sci. 231

Na M, Park H, Ahn M, Lee H and Chung I 2010 J. Nanosci. Nanotechnol. 106992

Nadargi D Y and Rao A V 2009 J. Alloys Compd 467397

Nakanishi T, Norisuye T, Sato H, Takemori T, Miyata Q T C, Sugimoto T and Nomura S 2007 Macromolecules 404165

Nistor C L, Donescu D, Perichaud A, Ballout W and Ghiurea M 2011a J. Sol-Gel Sci. Technol. 57164

Nistor C L, Donescu D, Ianchis R, Spataru C, Raditoiu V, Petcu C, Ghiurea M and Deleanu C 2011b J. Sol-Gel Sci. Technol. 5948
Owens D K and Wendt R C 1969 J. Appl. Polym. Sci. 131741

Park I, Ko S H, An Y S, Choi K H, Chun H, Lee S and Kim G 2009 J. Nanosci. Nanotechnol. 97224

Pescarmona P P and Maschmeyer T 2001 Aust. J. Chem. 54 583

Prasad A J K, Shashidhara S M and Muralidhara B K 2011 Bull. Mater. Sci. 34339

Redón R, Vázquez-Olmos A, Mata-Zamora M E, OrdóñezMedrano A, Rivera-Torres F and Saniger J M 2005 J. Colloid Interf. Sci. 287664

Rikowski E and Marsmann H C 1997 Polyhedron 163357

Shchipunov Y A, Kojima A and Imae T 2005 J. Colloid Interface Sci. 285574

Sun C, Ge L Q and Gu Z Z 2007 Thin Solid Films $\mathbf{5 1 5} 4686$

Sun M, Luo C, Xu L, Ji H, Ouyang Q, Yu D and Chen Y 2005 Langmuir 218978

Tabatabaei S, Shukohfar A, Aghababazadeh R and Mirhabibi A 2006 J. Phys. Conf. Ser. 26371

Uricanu V, Donescu D, Banu A G, Serban S, Olteanu M and Dudau M 2004 Mater. Chem. Phys. 85120

Venkatathri N 2007 Bull. Mater. Sci. 30615

Voronkov M G and Lavrent'yev V I 1982 Top. Curr. Chem. 102 199

Wang G, Yang J and Shi Q 2011 J. Coat. Technol. Res. 853

Wenzel R N 1936 Ind. Eng. Chem. 28988

Wu Z, Han H, Han W, Kim B, Ahn K H and Lee K 2007 Langmuir 237799

Xiao Y, Shen J, Xie Z, Zhou B and Wu G 2007 J. Mater. Sci. Technol. 23504

Xie Q D, Xu J, Feng L, Jiang L, Tang W H, Luo X D and Han C C 2004 Adv. Mater. 16302

Yao L F, Wang S, Li L, Xu R Q, Chen Y P and Kang J L 2011 Adv. Mater. Res. 194-1962300

Yao Y H, Dong X, Hong S, Ge H L and Han C C 2006 Macromol. Rapid Commun. 271627

Yoon K H and Kim M W 2001 Mol. Cryst. Liq. Cryst. 371365

Youngblood J P and McCarthy T J 1999 Macromolecules 326800

Yu Y Y, Chien W C and Lai C L 2009 J. Nanosci. Nanotechnol. 9 4135 